\title{
Getting out and about with arthritis: or not?
}

\author{
M A Chamberlain
}

In September 1990 disabled demonstrators held up traffic in Oxford St, London, causing chaos. Why were they moved to do so? And, perhaps almost as important, why did society see fit to drop the charge of obstruction served on 14 of these people?

The demonstrators were protesting against the inaccessibility of buses and trains. Why should they need to do so, given the Chronically Sick and Disabled Persons Act of 1970 and its subsequent amendments and additions? There were high hopes then: indeed, Baroness Darcy de Knayth, herself disabled, said in her maiden speech to the House of Lords, 'I wish to give my fullest support to this humane and extensive bill. . . . It plans to sweep away many of the obstacles to mobility'. In what way have the expectations of 1970 been so poorly realised that 20 years later disabled people, who must include amongst them vast numbers of people with arthritis, the commonest cause of loss of mobility-in what way have they been so poorly served?

Their complaints are many. In a recent Arthritis News ${ }^{1}$ there is discussion of the equation rheumatologists know well-is it worth subjecting the arthritic person to a possibly cold, long, and bumpy journey in an ambulance for $20-40$ minutes of comforting and useful physiotherapy. Often the answer is in the negative.

Currently, an argument is going on in the pages of the Yorkshire Evening Post and the council chambers of Leeds City Council. Disabled people do not view an extension of pedestrianisation of the city centre with pleasure. They accept that it may be necessary for the city's prosperity, but they fear the offer of parking in a multistorey car park at the periphery of the shopping area or with travel by access bus will bring them so many problems that shopping will become unsustainable. They envisage long cold waits for infrequent buses and they know they will find it hard to carry their shopping. It is known that of people with arthritis attending outpatients, only half will be able to walk 100 yards. ${ }^{2}$ Are city planners and transportation engineers aware of such constraints, including those of the energy necessary to perform normal tasks with joints that are persistently painful and function inefficiently? Let us consider the movements of a middle aged woman with arthritis who walks on crutches and wishes to do her shopping and then enjoy some leisure. Her difficulties will be illustrative of those of a wider group of people with arthritis, whether working or not.

The first issue will be the threshold of the house. Is there level access with convenient handrails and can the front door be opened and closed without the need for great force or uncomfortable gripping? Does the shopper have a car, parked conveniently and with appropriate controls, adapted if necessary?

When this car is driven into the town it has to be

University of Leeds, 36 Clarendon Road, Leeds LS2 9NZ M A Chamberlain properly designed, convenient to the services being used (and not used by able bodied persons)?

The person now has to walk to the shops. Is the surface of the pavement level, or, as in our suburb, of cracked, slippery, and uneven flagstones. For someone with arthritis of the hips with a small intermalleolar separation, kerb height is crucial. For those who are slow in walking, can the roads be crossed before speeding traffic bears down on them?

How does our patient go around the shop of her choice? In many stores ladies' clothing is upstairs or downstairs. Do the steps have rails on both sides? Are the length of the step and its height comfortable? Is there somewhere to sit and ease the painful joints (there rarely is)? What about changing rooms? Some are tiny, again with no chair. Others are vast open areas full of nubile young women prancing happily across the room considering their clothes in a full length mirror. A congenial place for the middle aged woman with arthritic joints?

Our patient might also wish to attend the theatre or cinema. Here, someone on crutches might be able to manage, given ramps of the correct gradient, or steps and stairs properly designed with good handrails. The same applies with other buildings for leisure, or work-including hospitals, many of which have poor access.

There are also major problems with transportation, particularly at the interfaces of various transport systems, and especially for wheelchair users. In Leeds, for instance, coaches arrive at a small, uncovered barren area with few facilities, and users have to walk some $\mathbf{3 0 0}$ metres to the railway station. But, at the nearby Bradford Interchange, rail, and bus, and coach are all housed under one roof with accessible services such as cafes and toilets.

The new designs of London taxis, the FX4 and the Metrocab, represent a major step forward. In addition to extra wide door openings and brightly coloured handles, these taxis carry ramps to load a wheelchair and its occupant directly onto the vehicle. But in many towns such taxis may not yet be available. At airports and railways staff will do what they can to help, particularly if given notice, but many railway stations are listed buildings which adapt badly. British Rail are fitting wheelchair accessible toilets with good grab handles for ambulant and elderly people in their new rolling stock.

New public buildings now have to be accessible to the disabled user; access has to be provided to all floors of new shops and offices and the ground floor of other premises used by the public. There is, however, a consultation document now circulating, which, if accepted, means access will have to be provided to all new non-domestic premises, and when certain alterations or extensions are made to 


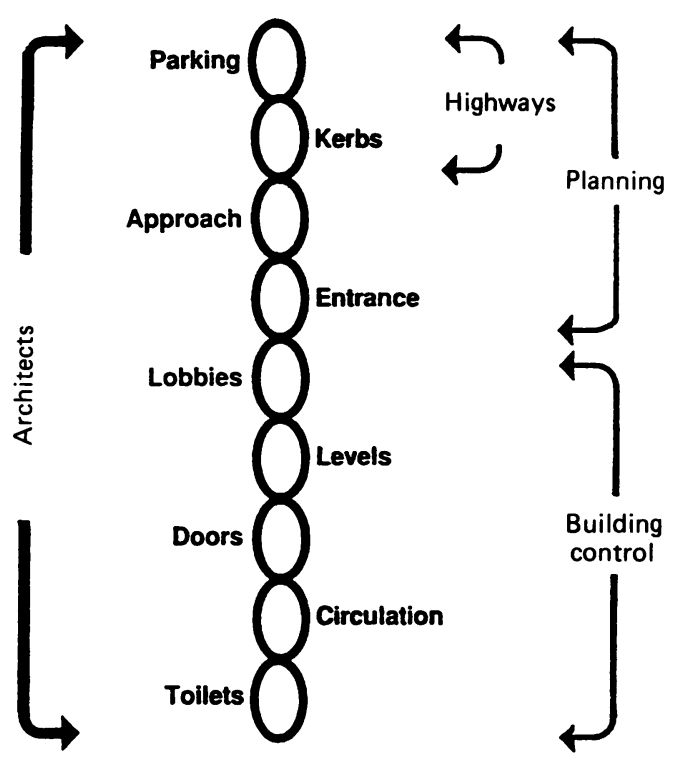

Figure 1 Stages in building and design for disabled people.

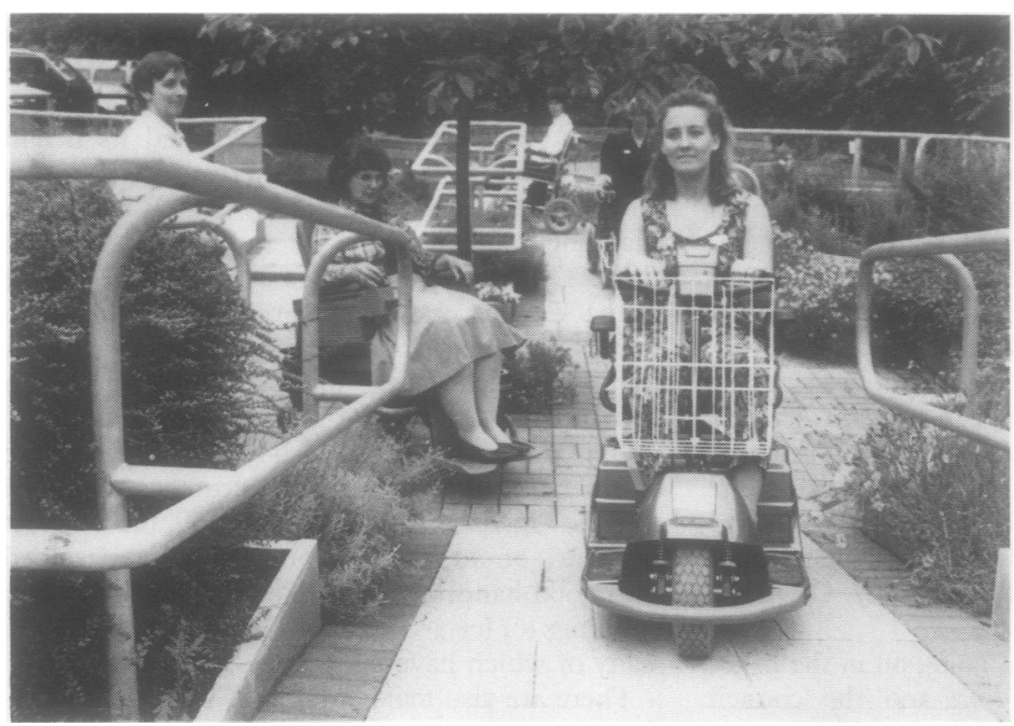

Figure 2 Students on a course at the William Merritt Disabled Living Centre trying out a variety of surfaces using various wheelchairs and crutches in the outdoor environmental area.

an existing building. Despite this legislation and frequently excellent design guidelines, many organisations, including hospitals, often neglect to make areas accessible. They fail to understand that meticulous attention to detail is necessary and do not realise that any broken or weak link in the chain of accessibility (fig 1) will result in the disabled person being quite unable to use the facilities put in with great good will. The problems are so common that one has to ask:

- Is the proper information available?

- What it is? Where is it?

- How should it be used?

- Why do failures occur?

Proper information Information on access is widely available. Paper information is held at all disabled living centres and local disablement information and advice lines (DIALs). The Access Committee for England published 'Design guidance notes for developers' and a series of useful leaflets is also available from the Centre for Accessible Environments.

Is proper information available to those who need $i t$ ? Those who need it, for access purposes, are: architects, planners, transportation engineers, builders.

Probably, many of these professionals do not use as much of the information as we would like. They and their students would benefit from the chance of experiencing good and bad design of external surfaces. We believe that some of the failure to use available information arises from lack of awareness of needs. We have therefore had built an external environmental area alongside our disabled living centre which incorporates not only good design but ramps which are too steep, steps with uneven treads, and poor surfaces. Courses mounted at the William Merritt Centre will not only give relevant information but will give experiential teaching (fig 2).

Finally, as has been pointed out to me by disabled people on many occasions, they themselves have the most detailed and relevant knowledge of their needs and thus should be consulted when questions of access arise. They need to participate at three levels: at the planning stage, with regard to specific project designs, and later keeping a watching brief. Finkelstein and other articulate disabled people believe that disability arises not from their bodily configuration but from the attitudes of society, which have resulted in the structures in which we exist. ${ }^{3}$ Not every disabled person would subscribe to this view, but most would agree with my colleague in DIAL who wrote to me (concerning this article): 'I feel the most important items to stress are: $(a)$ professionals to listen to what disabled people see as the problems ... not all of us are wheelchair users; (b) the growing movement of disabled people themselves, doing things for themselves; $(c)$ the main problem for disabled people is not necessarily the disability but the barriers we encounter not just in the physical environment but attitudes of society'.

Rheumatologists can help by supporting the attitudinal shift, encouraging a heightened awareness of their patients' wish for involvement in the planning process and urging those who plan our environment to use the expertise they have available.

\section{Sources of information}

1 Access Committee for England, 35 Great Smith St, London SWIP 3BJ. Design guidance notes for developers.

2 Centre for Accessible Environments, 35 Great Smith St, London SW1P 3BJ.

3 Royal Association for Disability and Rehabilitation. (RADAR), 25 Mortimer St, London W1N 8AB. Access data sheets.

4 Disabled living centres.

5 Disablement Information and Advice Line (DIAL), Park Lodge, St Catherine's Hospital, Tickhill, Balby, Doncaster DN4 8QN.

6 British Rail leaflets, British Airways, etc.

This article would have been considerably poorer without the great help of Mr Arthur Goldthorpe, previous chair, Access Committee for England, and Mrs Martha Morrill, honorary secretary/organiser, DIAL, Leeds.

I am also grateful for the help of the staff of the William I am also grateful for the help of the staff of the William
Merritt Disabled Living Centre, Leeds, and for secretarial Merritt Disabled Living Centre, Leeds, and for
assistance from Mrs J Packter and Mrs B Glossop.

1 Anonymous. Getting to hospital makes you sick. Arthritis Anonymous. Getting to
News 1990; No 47: 1 .

2 Chamberlain M A, Buchanan J. The arthritic in an urban environment. Ann Rhewm Dis 1979; 38: 51-6.
. The

3 Finkelstein V. Attitudes and disabled people: issues for discussion. In: Intemational exchange of information in rehabilitation. Monograph No 5. New York: World Rehabilitation Fund, 1980: 107. 